\title{
Time-resolved luminescent VUV-spectroscopy of pure and doped by rare earth ions crystals of strontium fluoride
}

\author{
K.V. Ivanovskikh*, V.A. Pustovarov, B.V. Shulgin \\ Experimental Physics Department, Ural State Technical University-UPI, Mira Street 19, 620002 Ekaterinburg, Russian Federation
}

Available online 2 March 2005

\begin{abstract}
The spectroscopic properties $\mathrm{SrF}_{2}-\mathrm{Eu}(1 \%), \mathrm{SrF}_{2}-\mathrm{Er}(1 \%)$ and nominal pure $\mathrm{SrF}_{2}$ crystals have been studied using time-resolved vacuum ultraviolet (VUV) spectroscopy under pulsed synchrotron radiation excitation. The $4 \mathrm{f}^{\mathrm{k}} \leftrightarrow 4 \mathrm{f}^{\mathrm{k}-1} 5 \mathrm{~d}$ (f-d) and $4 \mathrm{f}^{\mathrm{k}} \leftrightarrow 4 \mathrm{f}^{\mathrm{k}}$ (f-f) excitation spectra and emission spectra (with and without of time resolution) have been investigated in the wide energy region at 8 and $295 \mathrm{~K}$. Moreover, the emission and excitation behaviors of intrinsic luminescence $\mathrm{SrF}_{2}$ have been studied at $8 \mathrm{~K}$, when the fast and slow components given by singlet and triplet relaxation of self-trapped excitons (STE) are observed. Special attention is devoted to VUV emission of $\mathrm{Er}^{3+}$-doped $\mathrm{SrF}_{2}$ due to spin-allowed and spin-forbidden $4 \mathrm{f}^{10} 5 \mathrm{~d} \rightarrow 4 \mathrm{f}^{11}$ transitions.
\end{abstract}

(C) 2005 Elsevier B.V. All rights reserved.

PACS: 76.30.Kg; 71.35.Cc; 71.20.Dg; 78.47.+ p

Keywords: VUV-spectroscopy; Synchrotron radiation; $\mathrm{SrF}_{2}$; Rare-earth ions

\section{Introduction}

The crystals with fluorite structure possess a set of unique physical and luminescent properties. They are practically feasible and can be grown to have sufficient size and optical quality to create optical media [1]. From the fundamental point of view, among other ionic crystals, the homologous series of fluoride of II group is a model for

\footnotetext{
*Corresponding author. Tel.: + 73433754876 ; fax: +73433743884 .

E-mail address: pva@dpt.ustu.ru (K.V. Ivanovskikh).
}

studying the most general objective laws of interaction of impure ion with matrix.

In the last few years significant interest has been shown in vacuum ultraviolet (VUV) spectroscopy of rare-earth (RE) ions doped into wide-gap crystals, which is determined by the necessity of creating new class of VUV-phosphors. Such materials are widely applied today. Major applications are in mercury-free fluorescent lamps and plasma display $[2,3]$.

In the present paper, the spectroscopic properties of $\mathrm{SrF}_{2}, \mathrm{SrF}_{2}-\mathrm{Eu}(1 \%)$ and $\mathrm{SrF}_{2}-\mathrm{Er}(1 \%)$ single crystals have been studied. Mechanisms of transfer 
of energy to impurity sites are analyzed. The measurements of luminescence and excitation spectra as well as decay kinetics of luminescence were carried out using of time-resolved luminescent spectroscopy under selective excitation by synchrotron radiation (SR) in VUV and soft X-ray energy regions.

\section{Samples and experimental details}

Samples for this investigation were single crystals $\mathrm{SrF}_{2}-\mathrm{Eu}(1 \%), \mathrm{SrF}_{2}-\mathrm{Er}(1 \%)$ and nominal pure $\mathrm{SrF}_{2}$ grown in fluoric atmosphere by means of modified Stokbarger technique at Pyshminsky pilot plant GIREDMED (Russia).

The measurements were carried out at the SUPERLUMI station of HASYLAB (DESY, Hamburg) [4]. Investigations by using soft X-ray have been performed at the BW3 beamline of HASYLAB and "Luminescence with time-resolution" station of storage ring VEPP-3 (Budker INP SR of RAS, Novosibirsk). The time-resolved measurements could be carried out in various time windows $\Delta t$ delayed with respect to SR pulses on $\delta t$. In this work, two independent time windows with $\Delta t_{1}, \delta t_{1}$ (fast component) and $\Delta t_{2}, \delta t_{2}$ (slow component) were used. For $\mathrm{SrF}_{2}$ values of windows were $\delta t_{1}=2.4 \mathrm{~ns}, \Delta t_{1}=15.2 \mathrm{~ns}, \delta t_{2}=$ $72 \mathrm{~ns}$, and $\Delta t_{2}=102 \mathrm{~ns}$, and for $\mathrm{SrF}_{2}-\operatorname{Er}(1 \%)$ they were $\delta t_{1}=0.6 \mathrm{~ns}, \Delta t_{1}=1.8 \mathrm{~ns}, \delta t_{2}=12 \mathrm{~ns}$, and $\Delta t_{2}=20 \mathrm{~ns}$. The excitation spectra were corrected for the wave-length-dependent variation using sodium salicylate. The emission spectra were not corrected for the spectral sensitivity of detection system.

\section{Experimental results and discussion}

The time-resolved emission spectra of $\mathrm{SrF}_{2}$ due to annihilation of STE are shown in Fig. 1. These spectra were obtained under excitation by photons with energy of $11.8 \mathrm{eV}$ at 295 and $8 \mathrm{~K}$. At $295 \mathrm{~K}$ the wide band of luminescence has a maximum of about $313 \mathrm{~nm}$ and is characterized only by a slow component. Luminescence at $8 \mathrm{~K}$ is submitted by two components: fast with maximum near $354 \mathrm{~nm}$

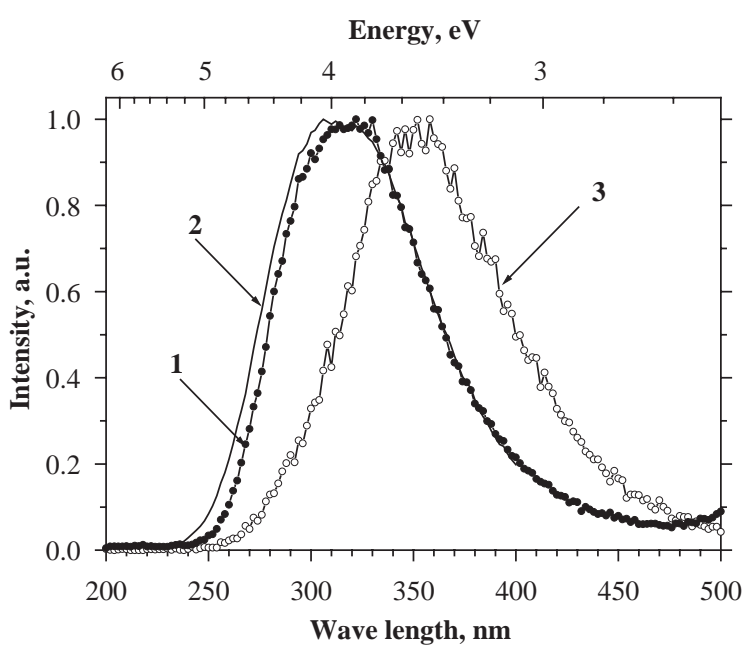

Fig. 1. Emission spectra of $\mathrm{SrF}_{2}$ at 295 (1) and $8.2 \mathrm{~K}(2,3)$, excited with $11.8 \mathrm{eV}$ photons: (1) time-integrated; (2) slow time window; (3) fast time window.

and slow with maximum near $317 \mathrm{~nm}$ whose contribution to the general light yield is dominating. According to Refs. [5,6], the fast component of intrinsic luminescence is due to spin-allowed singlet-singlet transitions of excitons and slow component is due to transitions from triplet level of excitons, which are possible because of presence of spin-orbit interaction.

The excitation spectra of triplet and singlet components of STE luminescence measured at $T=8 \mathrm{~K}$ are presented in Fig. 2. They show distinctions that confirm similar results received earlier by group [6] at $90 \mathrm{~K}$. The position of threshold of excitation of the slow component of luminescence corresponds to the beginning of fundamental absorption of crystal $\mathrm{SrF}_{2}$ and creation of excitons with the least energy. It is submitted as a long-time increasing peak of excitation in an interval of $8-10.3 \mathrm{eV}$. The spectrum of excitation of fast components, on the contrary, is characterized by sharp increase of intensity of a luminescence at excitation near $10.1 \mathrm{eV}$ with a maximum at $10.4 \mathrm{eV}$. The fast component is most effectively excited at 10.4 and $11.2 \mathrm{eV}$. At a greater energy of photons, excitation intensity of fast component makes no more than $25 \%$ concerning those in the field of fundamental 


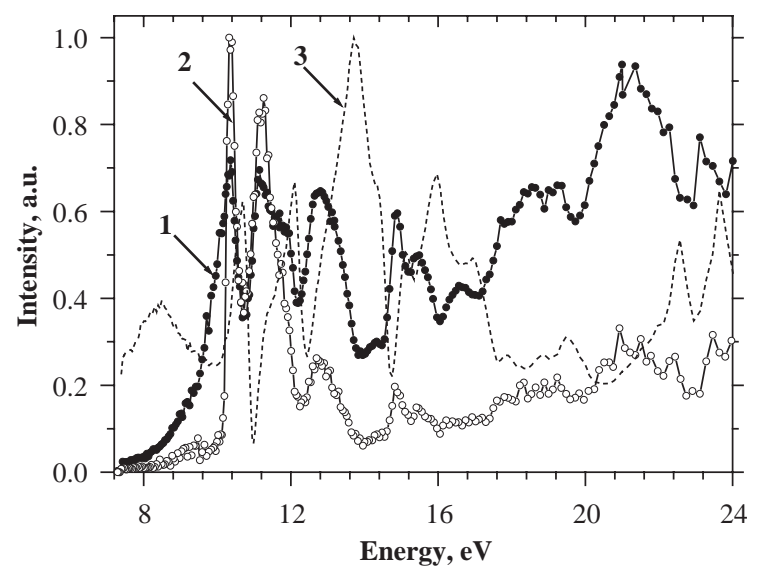

Fig. 2. Excitation spectra of STE-luminescence of $\mathrm{SrF}_{2}$ recorded in slow (1) and fast (2) time windows at $8 \mathrm{~K}$; (3) reflectivity spectrum at $8 \mathrm{~K}$.

absorption. Excitation intensity of slow components has rather high values both in the field of direct optical creation of excitons and electronhole pairs, and in the field of multiplying of photons. It is necessary to note, also, that band near $11.8 \mathrm{eV}$ in excitation spectrum of fast components was not observed.

A prominent feature of self-trapped excitions (STE) luminescence of $\mathrm{SrF}_{2}$ is the big size of Stokes shift. It is equal from 5.4 and $5.6 \mathrm{eV}$ (for slow component at 295 and $8 \mathrm{~K}$, respectively) up to $6.7 \mathrm{eV}$ (for fast component at $8 \mathrm{~K}$ ). It unambiguously points to the significant participation of electron-phonon interaction during a relaxation of excitations and for the fast component shown only at low temperatures, its degree appeared more strongly.

The luminescence of crystal $\mathrm{SrF}_{2}-\mathrm{Eu}(1 \%)$ is submitted by an intensive wide band with maximum near $420 \mathrm{~nm}$ and by low-intensity band near $589 \mathrm{~nm}$ which are due to the $4 \mathrm{f}^{6} 5 \mathrm{~d} \rightarrow 4 \mathrm{f}^{7}\left({ }^{8} \mathrm{~S}_{7 / 2}\right)$ in $\mathrm{Eu}^{2+}$ and ${ }^{5} \mathrm{D}_{0} \rightarrow{ }^{7} \mathrm{~F}_{1}$ in $\mathrm{Eu}^{3+}$ sites, respectively [7]. Fig. 3 shows the excitation spectrum of emission due to $4 \mathrm{f}^{6} 5 \mathrm{~d}\left(\mathrm{E}_{\mathrm{g}}\right) \rightarrow{ }^{8} \mathrm{~S}_{7 / 2}$ transition in $\mathrm{Eu}^{2+}$. The basic bands of excitation lay in the field of transparency of substance $\left(\mathrm{E}_{\text {exc }}<10 \mathrm{eV}\right)$ and correspond to transition from the lowest Stark component of the $4 \mathrm{f}^{7}$-configuration to the excited states $T_{2 g}$ and $E_{g}$ of the $4 f^{6} 5 d$ configuration [7]. At $\mathrm{E}_{\mathrm{exc}}>10 \mathrm{eV}$, excitation remains rather effective

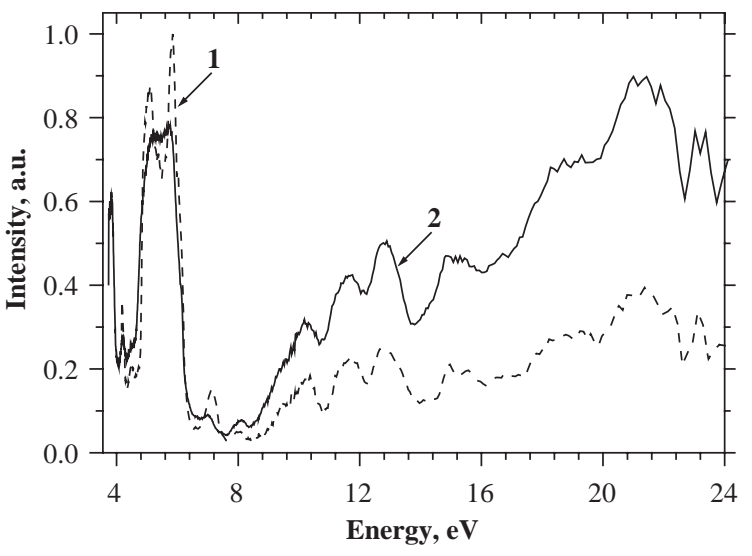

Fig. 3. Excitation spectra of $\mathrm{SrF}_{2}-\mathrm{Eu}(1 \%)$ recorded monitoring the $4 \mathrm{f}^{6} 5 \mathrm{~d} \rightarrow 4 \mathrm{f}^{7}\left({ }^{8} \mathrm{~S}_{7 / 2}\right)$ emission of $\mathrm{Eu}^{2+}$ at $420 \mathrm{~nm}$ at $8 \mathrm{~K}$ (1) and $295 \mathrm{~K}(2)$.

and is due to transfer of energy from matrix that is well observed on conformity of excitation bands of $\mathrm{Eu}^{2+}$ and STE luminescence (compare Fig. 1). At low temperature this mechanism weakens.

For $\mathrm{Er}^{3+}$ the states of $4 \mathrm{f}^{10} 5 \mathrm{~d}$ configuration are situated at a higher energy than for $\mathrm{Eu}^{2+}$. Excitation of the basic luminescence band at $551 \mathrm{~nm}$ of $\mathrm{Er}^{3+}$ given by ${ }^{4} \mathrm{~S}_{3 / 2} \rightarrow{ }^{4} \mathrm{I}_{15 / 2}$ takes place in the field of transparency of a crystal (Fig. 4). Light yield of slow components prevails. At $8 \mathrm{~K}$ as well as at room temperature, the most effective excitation is shown in an interval of 7.1-9.2 eV. In the field of excitation of $9.2-10.5 \mathrm{eV}$ at $8 \mathrm{~K}$ the emission is suppressed and it is the basic difference in spectra at 8 and $295 \mathrm{~K}$. At the further increasing of energy of incident photons the efficiency of excitation at $8 \mathrm{~K}$ falls, but at $295 \mathrm{~K}$ it remains at the level no more than $20 \%$. All these features allow one to assume a change in energy transfer mechanisms from matrix to impurity in the $\mathrm{SrF}_{2}-\mathrm{Er}^{3+}$ system at temperature pulldown.

The important part of our research is the study of VUV-luminescence properties of $\mathrm{SrF}_{2}-\mathrm{Er}$ connected with high-energy $4 \mathrm{f}^{10} 5 \mathrm{~d} \rightarrow 4 \mathrm{f}^{11}$ transitions. Fig. 5 shows a time-resolved VUV-emission spectra of $\mathrm{SrF}_{2}-\mathrm{Er}(1 \%)$ at $8 \mathrm{~K}$, excited by $140 \mathrm{eV}$ soft X-ray. The spectra demonstrate bands at 146.4 and $164.5 \mathrm{~nm}$ in the fast and slow time windows, respectively. The first band can be assigned to spin-allowed transition from the one 


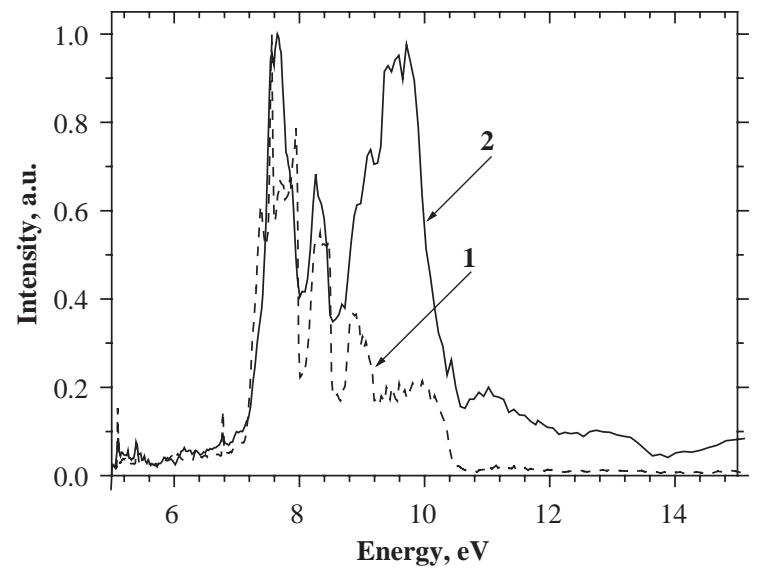

Fig. 4. Excitation spectra of $\mathrm{SrF}_{2}-\mathrm{Er}(\%)$ without time resolution recorded monitoring the ${ }^{4} \mathrm{~S}_{3 / 2} \rightarrow{ }^{4} \mathrm{I}_{15 / 2}$ emission at $551 \mathrm{~nm}$ at $8 \mathrm{~K}$ (1) and $295 \mathrm{~K}$ (2).

of high lying $4 \mathrm{f}^{10} 5 \mathrm{~d}$ states to the ground state ${ }^{4} \mathrm{I}_{15 / 2}$. Accordingly, the second band of emission, which determines VUV-emission light yield of $\mathrm{SrF}_{2}-\mathrm{Er}$, is due to spin-forbidden transition from the high-spin (HS) $4 \mathrm{f}^{10} 5 \mathrm{~d}$-state (sextet) to the ground-state ${ }^{4} \mathrm{I}_{15 / 2}$ and determines VUV-emission light yield [8-10]. The excitation spectra of the $4 \mathrm{f}^{10} 5 \mathrm{~d}(\mathrm{HS}) \rightarrow{ }^{4} \mathrm{I}_{15 / 2}$ emission are presented in Fig. 6. A number of broad bands is observed, some of which have a fine structure. Transitions to the higher $5 \mathrm{~d}$ crystal field components are observed at $8.05,8.53,9.24$ and at $9.59 \mathrm{eV}$ (weakly). Distinction of excitation spectra measured at 8 and $295 \mathrm{~K}$ is characterized by widening of main bands at $295 \mathrm{~K}$. At $8 \mathrm{~K}$ the low-intensive bands at 7.77 and $8.89 \mathrm{eV}$ appeared. The band at $7.77 \mathrm{eV}$ can be assigned to the spin-forbidden $\mathrm{f}$-d-transition. Comparison of excitation spectra obtained monitoring $4 \mathrm{f}^{10} 5 \mathrm{~d}(\mathrm{HS}) \rightarrow{ }^{4} \mathrm{I}_{15 / 2}$ and ${ }^{4} \mathrm{~S}_{3 / 2} \rightarrow{ }^{4} \mathrm{I}_{15 / 2}$ emissions (Fig. 6) shows their slope opposition, which reflects a competition of processes of transfer of excitation energy to emitting levels of $4 \mathrm{f}^{10} 5 \mathrm{~d}$ and $4 \mathrm{f}^{11}$ configurations in $\mathrm{Er}^{3+}$.

\section{Summary}

We have investigated spectroscopic properties of $\mathrm{SrF}_{2}, \mathrm{SrF}_{2}-\mathrm{Eu}(1 \%), \mathrm{SrF}_{2}-\mathrm{Er}(1 \%)$ crystals. The

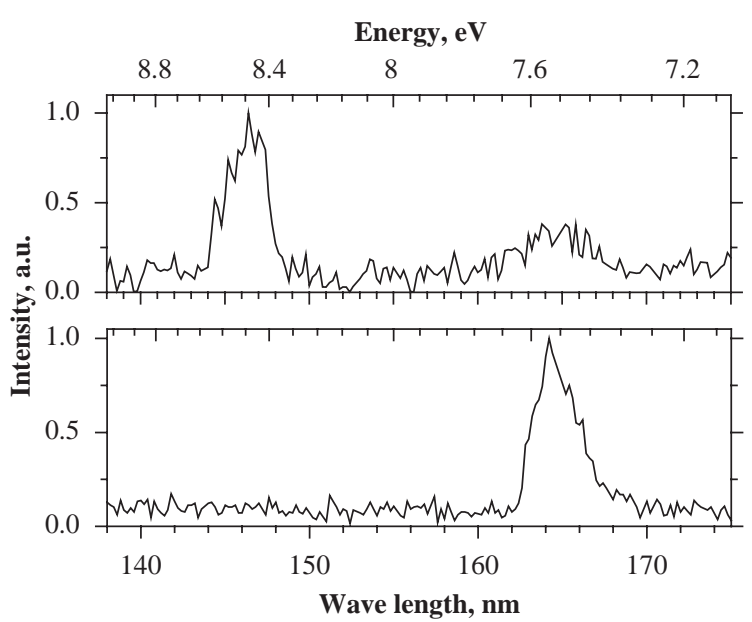

Fig. 5. VUV-emission spectra of $\mathrm{SrF}_{2}-\mathrm{Er}(1 \%)$ at $10 \mathrm{~K}$, excited with $140 \mathrm{eV}$ soft X-ray photons: fast time window (upwardly); slow time window (below).

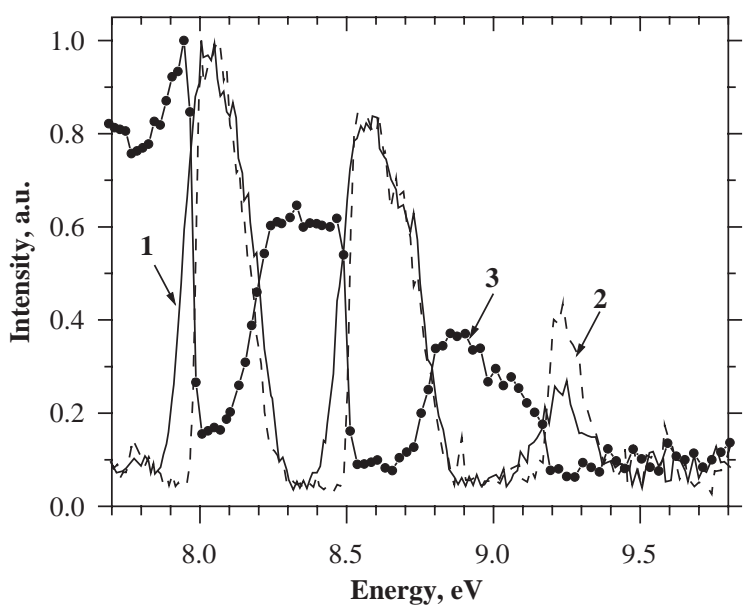

Fig. 6. Excitation spectra of $\mathrm{SrF}_{2}-\mathrm{Er}(\%)$ without time resolution recorded monitoring the $4 \mathrm{f}^{10} 5 \mathrm{~d}(\mathrm{HS}) \rightarrow{ }^{4} \mathrm{I}_{15 / 2}$ emission at $164.5 \mathrm{~nm}$ at $8 \mathrm{~K}$ (1) and $295 \mathrm{~K}$ (2) in comparison with excitation spectrum of ${ }^{4} \mathrm{~S}_{3 / 2} \rightarrow{ }^{4} \mathrm{I}_{15 / 2}$ emission at $551 \mathrm{~nm}$ at $8 \mathrm{~K}(3)$.

low-temperature intrinsic luminescence of $\mathrm{SrF}_{2}$ is due to emitted relaxation of singlet and triplet states of STE and is characterized by a large magnitude of Stokes shift (up to $6.7 \mathrm{eV}$ for singlet components). The basic differences of excitation of singlet and triplet components take place in the field of energy threshold of creating of excitons. 
On analyzing the excitation spectra of doped crystals, it was shown that efficiency of energy transfer from matrix to emitted $\mathrm{RE}$ sites in $\mathrm{SrF}_{2}-\mathrm{Eu}(1 \%)$ is higher than in the $\mathrm{SrF}_{2}-\operatorname{Er}(1 \%)$.

The most intensive bands of VUV emission of $\mathrm{Er}^{3+}$ introduced into $\mathrm{SrF}_{2}$ were detected at 146.4 and $164.5 \mathrm{~nm}$ and assigned, respectively, to interconfiguration transitions from LS and HS states of $4 \mathrm{f}^{10} 5 \mathrm{~d}$-configuration to the ground-state ${ }^{4} \mathrm{I}_{15 / 2}$. Analyses of excitation behavior of $\mathrm{f}-\mathrm{f}$ and $\mathrm{d}-\mathrm{f}$ luminescence show competition of emitted relaxation from the levels of $4 \mathrm{f}^{10} 5 \mathrm{~d}$ and $4 \mathrm{f}^{11}$ configurations.

\section{Acknowledgements}

Research was supported by RFBR (02-0216322), the RF Ministry of Education (E02-3.4362), grant "Universities of Russia" (UR.02.01.023) and CRDF (Rec. 005). We thank A.P. Syryanov
(SB of NIKIET) for providing crystals and $\mathrm{M}$. Kirm (Hamburg University) for his assistance in experimental setup.

\section{References}

[1] K.A. Kalder, Proceedings of Institute of Physics and Astronomy of Estonia's AS, vol. 42, 1974, p. 81.

[2] A.N. Belsky, J.C. Krupa, Displays 19 (1999) 185.

[3] C.R. Ronda, T. Justel, H. Nikol, J. Alloy. Compd. 275-277 (1998) 669.

[4] G. Zimmerer, Nucl. Instr. and Meth. A 308 (1991) 178.

[5] N.N. Ershov, N.G. Zakharov, P.A. Rodny, Opt. Spectrosc. (USSR) 53 (1) (1982) 89.

[6] Yu.M. Alexandrov, V.N. Makhov, P.A. Rodny, et al., Fiz. Tverd. Tela 28 (9) (1986) 2853.

[7] O.J. Rubio, J. Phys. Chem. Solids 52 (1) (1991) 101.

[8] L. van Pieterson, M.F. Reid, R.T. Wegh, A. Meijerink, J. Lumin. 94-95 (2001) 79.

[9] J. Becker, J.Y. Gesland, N.Yu. Kirikova, et al., J. Alloy. Compd. 275-277 (1998) 205.

[10] L. van Pieterson, M.F. Reid, R.T. Wegh, A. Meijerink, Phys. Rev. Lett. 88 (6) (2002) 067405. 